\title{
Gender Associated Differences in Developmental Parameters of Corcyra cephalonica (Stainton) (Lepidoptera: Pyralidae)
}

\author{
K.C. Sowjanya*, M. Thippaiah and K. Murali Mohan
}

Department of Agricultural Entomology, GKVK, Bengaluru, Karnataka, India

*Corresponding author

\section{A B S T R A C T}

\section{Keywords \\ Corcyra cephalonica, Developmental period, Larval instars \\ Article Info \\ Accepted: \\ 18 August 2018 \\ Available Online: \\ 10 September 2018}

The developmental biology of Corcyra cephalonica (Stainton) (Lepidoptera: Pyralidae) was studied. Male and female larval developmental period, larval instars, pupal and total developmental were recorded. Both male and female larvae passed 7 to 8 instars. However, most of them passed 7 instars. Male larvae took an average of $31.3 \pm 1.8$ days and female larvae completed development in $32.5 \pm 3$ days. Male completed pupal period in an average of $9.3 \pm 1.1$ days and female pupae took an average of $11.3 \pm 0.94$ days to complete its development. This study revealed, the longer developmental period of females as compare with the males. Females completed total developmental period from egg to adult, ranged from 42 to 55 days with an average of 48.9 days. Males took 42 to 51 with an average 45.3 days for completion of total development at $27 \pm 1.6{ }^{\circ} \mathrm{C}$ and $46 \pm 5$ per cent.

\section{Introduction}

Rate of growth of the population may vary from time to time depending on the various factors, which may also include developmental period taken by individuals. This could vary from one individual to another. This variation in each and every developmental stage could accumulate between and within the sexes. When there will be a variation in developmental period of male and female, certainly it affects the respected individual's activities, especially emergence of male and female from the population. Studies on this type of aspects could be easily carryout by using the insects especially with stored product insect pests. Since, most of these insects are studied well with respects to biology and feeding behavior. One such a stored product insect pest in Corcyra cephalonica (Stainton) belongs to the order Lepidoptera and family Pyralidae. They have been no clear reports are documented regarding gender associated developmental difference in Corcyra cephalonica.

\section{Materials and Methods}

\section{Eggs}

Corcyra cephalonica eggs were inoculated on egg card. The hatched larvae were removed from egg card by using camel hair brush. These hatched larvae were used for individual observation and to record the various developmental periods. 


\section{Larval period and number of instars in $C$. cephalonica}

The larvae, after hatching, were transferred individually to plastic vial $\left(24.7 \mathrm{~cm}^{3}\right)$ using camel hair brush. Sufficient quantity of sterilized sorghum grains was provided in the plastic vial to support the larval development. Larval instars were recorded by counting the number of head capsules. Head capsules that were collected from each individual vial and observations were carried till the larva entered pupation. Collected capsules were transferred to vial containing 70 per cent ethyl alcohol. At the end, total number of head capsules from each individual larva was recorded.

Larval period was recorded by counting the number days taken from egg hatching to pupation. Sex of the individual was determined at the pupal stage by looking into the slit on eighth abdominal segment of pupae.

\section{Pupal period in C. cephalonica}

Once larvae entered pupation, tough webs was dissected using the micro scissor and pupae were carefully taken out from web (photo 1). Sex of pupae noted based on slit on eighth abdominal segment of pupae (photo 2). The pupae were individual kept and monitored daily, to note moth emergence. Pupal period was estimated based on the time take from the day of pupation till the adult emergence.

\section{Statistical analysis}

Two sampled T- test was used to compare the gender associated developmental parameters

\section{Results and Discussion}

During the study, larval period, number of larval instars, pupal period and total number of days taken by male and female individuals were recorded.

\section{Larvae}

Total larval period ranged from 27 to 39 days $\left(27 \pm 1.6{ }^{\circ} \mathrm{C}\right.$ and $\left.46 \pm 5 \% \mathrm{RH}\right)$. Males took an average of $31.3 \pm 1.8$ days and females took in $32.5 \pm 3$ days to larval development. Statistically larval developmental period among the male and female differed significantly at 5 per cent (Table 1). Similar gender associated difference in the larval period was noticed by Manjunath (1993), who recorded average of 29.97 and 30.92 days of larval period for males and females, respectively. However, in contrast to the present findings, Ayyar (1934) reported longer larval developmental period (66 days) on cowpea diet. This variation could be due to differences in the diets used in these different studies.

Most of the larvae passed 7 instars and few larvae passed 8 instars (Table 2). The present results are in agreement with study of Seshagiri Rao (1954), who recorded the 8 instars in some larvae and 6 or 7 instars in other larvae of $C$. cephalonica. And his opinion regarding number of larval instar was that, larval instars varied with sex, food and existing conditions.

However, in the present study both the male and female larvae showed variation, though, they were reared under same identical rearing conditions.

\section{Pupae}

The pupal developmental period was completed in 8-12 days with an average of 9.3 \pm 1.1 days. Male completed pupal period in an average of $9.3 \pm 1.1$ days and female pupae took an average of $11.3 \pm 0.94$ days to complete its development. There was statistical difference among males and female at 1 per cent level of significance, which is represented in table 2. 
The present study confirms the findings of Ayyar (1934), Patel and Patel (2007), Nasrin (2016), Pruthi and Singh (1950), Atwal (1976), Thomas (1961), Shazali and Smith (1986). However, different pupal developmental period in contrast to the current findings is reported Patel (2011) with 14 days and Bhubaneshwari et al., (2013) upto 16 days.

The total developmental period (egg, larval and pupal period) completed in 42 to 55 days at $27 \pm 1.6^{\circ} \mathrm{C}$ and $46 \pm 5 \%$ of $\mathrm{RH}$ on sorghum diet. Females completed total development (egg to adult) ranging from 42 to 55 days with an average of 48.9 days. Males took 42 to 51 with an average 45.3 days for completion of total development. Total developmental period of male and female were significantly different at $5 \%$ and $1 \%$ level of significance (Table 1).

These results were comparable with the studies of Ayyar (1934), who recorded total developmental period of 42 on wheat, 53 days on rice and 57 days on sorghum. On broken maize, 47 to 57 days with an average of 48.6 days of developmental period was recorded by Seshagiri Rao (1954). Results of the other workers' studies (Etman et al., 1988, Bartels, 2002, Chowdary and Senapathi, 2015) also supported the present investigation findings. Contrary to this study, many investigators observed upto 69 days for completion of total development (Osman, 1986, Haritha et al., 2000 and Limont et al., 2009).

Table.1 Gender associated differences in larval instars in Corcyra cephalonica

\begin{tabular}{|c|c|c|c|}
\hline $\begin{array}{c}\text { Sex of } \\
\text { larvae }\end{array}$ & $\begin{array}{c}\text { Number of } \\
\text { individual }\end{array}$ & $\begin{array}{c}\text { Number of head } \\
\text { capsule }\end{array}$ & $\begin{array}{c}\text { Number of larval } \\
\text { instars }\end{array}$ \\
\hline \multirow{2}{*}{ Female } & $32(86.5 \%)$ & 6 & 7 \\
\hline \multirow{2}{*}{ Male } & $5(13.5 \%)$ & 7 & 8 \\
\hline & $43(93.5 \%)$ & 6 & 7 \\
\hline
\end{tabular}

Table.2 Gender associated statistical difference in developmental biology of Corcyra cephalonica

\begin{tabular}{|c|c|c|c|c|c|}
\hline Sex & Male & Female & t-Statistic & \multicolumn{2}{|c|}{ Table value } \\
\hline $\begin{array}{c}\text { Number of } \\
\text { individuals } \\
\text { observed }\end{array}$ & 46 & 37 & & & \\
\hline $\begin{array}{c}\text { A verage larval } \\
\text { period(days) }\end{array}$ & $31 \pm 1.8$ & $32.5 \pm 3$ & $-2.0 *$ & $0.01 \%$ \\
\hline $\begin{array}{c}\text { A verage pupal } \\
\text { period(days) }\end{array}$ & $9.3 \pm 1.1$ & $11.3 \pm 0.9$ & $-9.0 * *$ & 2.0 & 2.7 \\
\hline $\begin{array}{c}\text { Average total } \\
\text { developmental } \\
\text { period(days) }\end{array}$ & $45 \pm 2.5$ & $48.8 \pm 3.3$ & $-5.3 * *$ & 2.0 & 2.7 \\
\hline
\end{tabular}


Photo.1 Corcyra cephalonica pupal webs and dissected web and pupa inside it
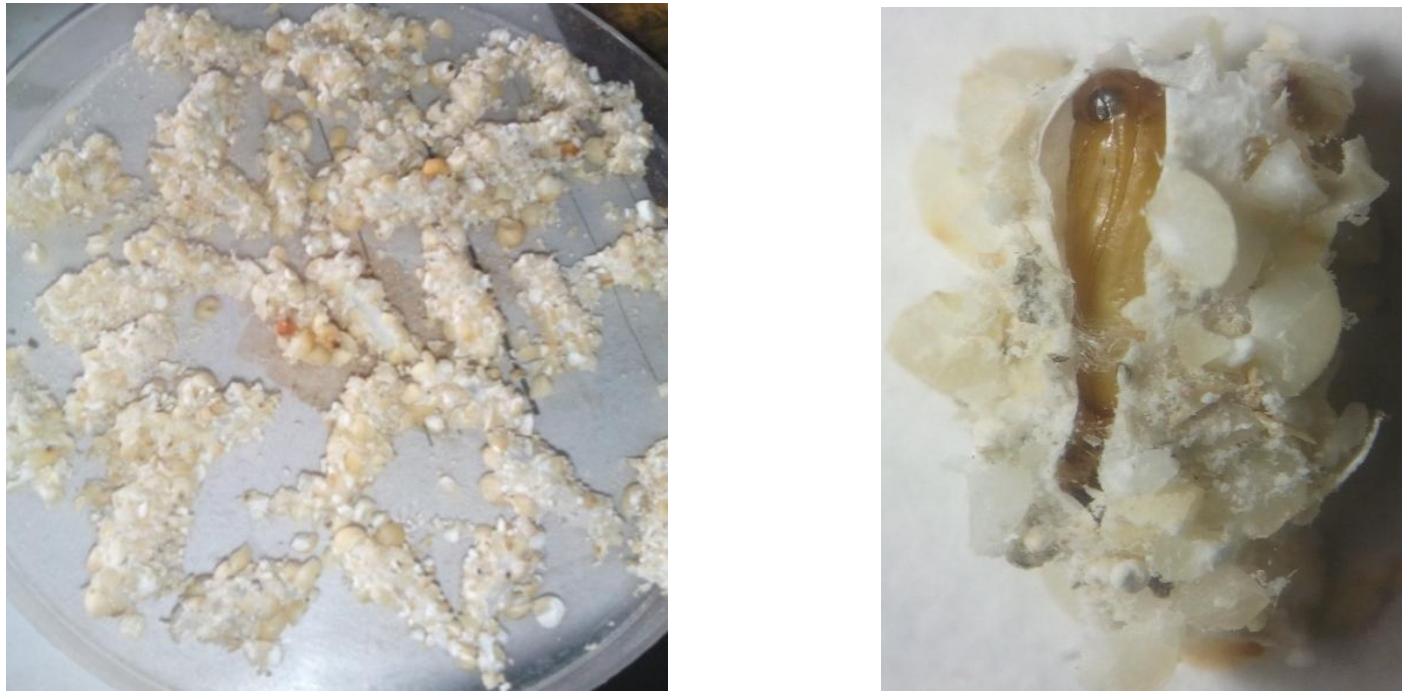

Photo.2 Corcyra cephalonica pupae

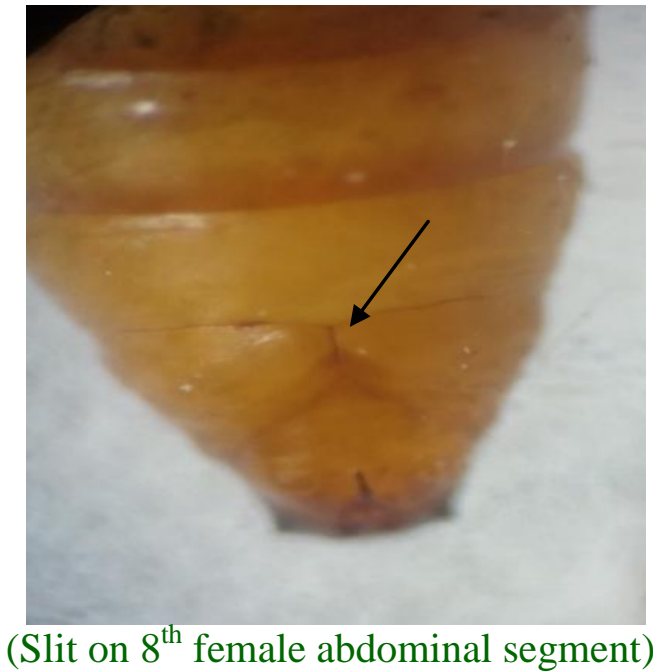

Gender associated difference in developmental biology

In this study, the time taken by male and female to complete the different developmental stages viz., larva, pupa and total life cycle was investigated.

Males were completed all the developmental period earlier as compare to females. These developmental periods were statistically differed, which was analyzed by two sampled

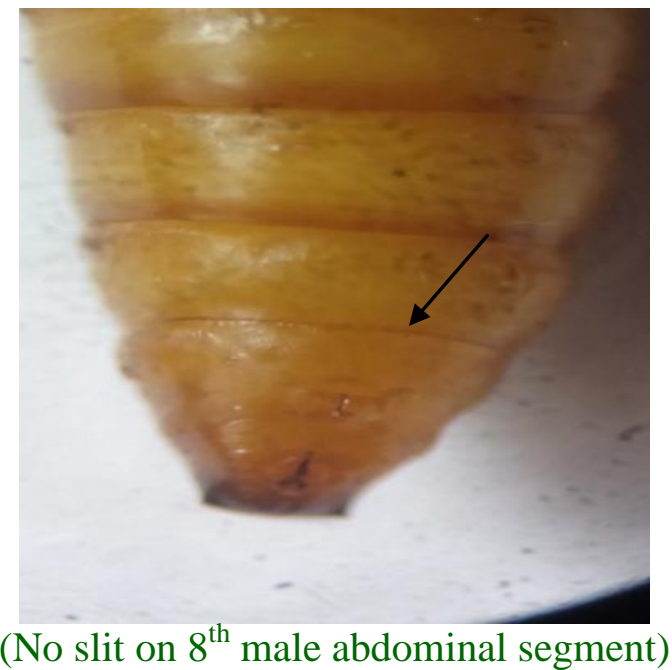

t test by using the software WASP (Web Agri Stat Programme).

Males completed larval period earlier than females. Males took an average of $31.3 \pm 1.8$ days to complete larval development and females completed larval development in $32.5 \pm 3$ days. Statistically larval developmental period among the male and female differed significantly at 5 per cent It was also observed that number of larval instars was not constant among the individuals 
studied. Both male and female larvae passed 7 to 8 instars. However, males completed the larval developmental period earlier than females. In both the sexes, number of instars varied from seven to eight. In case of males of C. cephalonica, 93.5 per cent of the larvae passed seven instars and only 6.5 per cent of larvae undergone eight instars. Same trend noticed in females of $C$. cephalonica, where 86.5 per cent of the larvae passed seven instars and 13.5 per cent passed eight instars. Details of the findings are presented in table 2 .

\section{Gender associated difference in pupal period}

Pupal period was noted by recording the time taken by individual from the day of pupation to adult emergence from each individual vial. Males were taken lesser time to complete the pupal development as compare to female's pupae. Male completed pupal period in an average of $9.3 \pm 1.1$ days and female pupae took an average of $11.3 \pm 0.94$ days to complete its development. There was statistical difference among males and female at 1 per cent level of significance, which is represented in table 1.

Apart from the pupal period, significant difference among male and female pupae was noticed with regard to the pupal size. Female pupae were larger in size as compare to male pupae. Average length of male pupa was $0.76 \pm$ $0.16 \mathrm{~cm}$ and the average length of female was $0.85 \pm 0.1 \mathrm{~cm}$.

\section{Gender associated differences in total developmental period in $C$. cephalonica}

Total developmental period of male and female were recorded in the prevailing laboratory temperature and relative humidity (RH). Total developmental period taken by males were less as compare to females developmental period. The differences in the developmental period were significantly different at 1 per cent level of significance. This significance difference was suggested by the WASP, statistical software, in which two sampled t test was carried.
Total developmental period taken by males and females were studied for one cycle. This study revealed the longer developmental period of females as compare with the males. Females completed total development from egg to adult was 42 to 55 with an average of 48.9 days.

Males took 42 to 51 with an average 45.3 days for completion of total development at $27 \pm 1.6$ ${ }^{0} \mathrm{C}$ and $46 \pm 5$ per cent. Total developmental period of male and female were significantly different at $5 \%$ and $1 \%$ level of significance.

\section{Acknowledgement}

First and foremost, I praise and thank God for giving me the strength and courage for successfully completing the task. I remain ever thankful to the teaching and non-teaching staff of Department of Agricultural Entomology for providing me the necessary assistance during my research work.

\section{References}

Atwal, A.S., 1976. Agricultural pests of India and South East Asia. pp. 392-394.

Ayyar, P. N. K., 1934. A destructive pest of stored products in South India, Corcyra cephalonica Stainton (Pyralidae: Lepidoptera). Bulletin of Entomological Research. 25(2): 155-169.

Bartels, D., 2002. Corcyra cephalonica Stainton- an overlooked pest? Bulletin. OILB/SROP., 25(3): 33-40.

Bhubaneshwari Devi, M., Victoria Devi, N., Rita Devi, S. and Ranabir Singh, P., 2013. Biology ans morphometric of Rice moth Corcyra cephalonica. Annals of Plant Protection Sciences., 21(1): 87-89.

Chaudhuri, N. B., and Senapati, S. K., 2015. Development and reproductive performance of rice moth Corcyra cephalonica Stainton (Lepidoptera: Pyralidae) in different rearing media. Journal of the Saudi Society of Agricultural Sciences. 
Cheng, W. Y. and Hung, T. K., 1990. Larval instars and development of Corcyra cephalonica. Report of the Taiwan sugar Research institute. 128; 23-30.

Etman, A. A., El-Sayed Ferial, M. A., Eesa, N. M. and Moursy, L. E., 1988. Laboratory studies on development, survival, mating behavior and reproductive capacity of the rice moth, Corcyra cephalonica (Stainton) (Lepidoptera., Galleriidae). Journal of apllied entomology., 106 (1-5): 232-240.

Haritha, V., vijayalakshmi, K. and Murthy, M. M. H., 2000. Biology of rice moth, Corcyra cephalonica Stainton on groundnut pods and kernels under controlled condition. Journal of applied zoological researches., 11(2/3): 135-136.

Jagadish, P. S., Nirmala, P., Rashmi, M.A., Jayalaxmi N. H. and Neelu Nangia, 2009. Biology of rice moth, Corcyra cephalonica Stainton on foxtail millet, Karnataka Journal of agricultural sciences., 22: 674-675.

Limonta, L., Locatelli, D. P., Broglia, T. and Baumugartne R, J., 2009. Cohort development models for integrated Corcyra cephalonica (Stainton) population management. Boll. Zool. Agr. Bachic., 41(3): 215-226.

Manjunath, T.M., 1993. Qualitative and quantitative analysis of techniques leadind to economic mass production of Corcyra cephalonica Stainton (Lepidoptera; Pyralidae). Ph. D. thesis, University of Agricultural Sciences, Bangalore.

Nasrin, M., Alam, M. Z., Miah, R. U. and Hossains, M. M., 2016. Effect of various cereals on the development of Corcyra cephalonica (Stainton) and its egg parasitoid Trichogramma chilonis (Ishii), Bangladesh Journal of Agricultural Research., 41(1): 183-194.

Osman, N., 1986. Development of the rice moth, Corcyra cephalonica (St.) on different grains. Pertanika., 9(2): 155-159.

Patel, R. A. and Patel, B. R., 2007. Comparative biology of rice moth, Corcyra cephalonica Stainton. Journal of Plant Protection and Environment., 4(1): 14-19.

Prakash, R. A. and Kumar, P. S., 2005. Biology of Corcyra cephalonica Stainton in important cereals and millets. Insect environment., 11(2): 86-87.

Pruthi, H.S. and Singh, M., 1950. Pests of stored grain and their control. Issued by I.C.A.R., pp.1-88.

Seshagiri Rao, D., 1954. Notes on rice moth Corcyra cephalonica Stainton (Lepidoptera: Gellerinae). Indian Journal of Entomology., 15: 95-144.

Shailaja, S, 2008. Biology and infestation behavior of rice meal moth, Corcyra cephalonica Stainton (Lepidoptera: Pyralidae) on proso millet, Panicum miliaceum (L.). M. Sc. Thesis, University of Agricultural Sciences, Bangalore.

Shazali, M.E.H. and Smith, R.H., 1986. Life history studies of internally feeding pests of stored sorghum: Sitotroga cerealella (OI) and Sitophilus oryzae (L.). Journal of Stored Products Research., 21: 171-178

Thomas, P. M., 1961. Control of rice moth in warehouses. No. CWC/Tech-1A/WH/6061.

\section{How to cite this article:}

Sowjanya, K.C., M. Thippaiah and Murali Mohan, K. 2018. Gender Associated Differences in Developmental Parameters of Corcyra cephalonica (Stainton) (Lepidoptera: Pyralidae). Int.J.Curr.Microbiol.App.Sci. 7(09): 2534-2539. doi: https://doi.org/10.20546/ijcmas.2018.709.315 